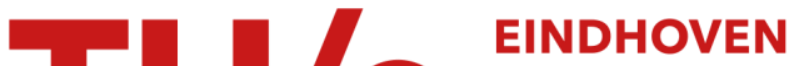 UNIVERSITY OF TECHNOLOGY
}

\section{Monolithic integration in fused silica: When fluidics, mechanics and optics meet in a single substrate}

\section{Citation for published version (APA):}

Bellouard, Y. J., Said, A. A., Dugan, M., \& Bado, P. (2009). Monolithic integration in fused silica: When fluidics, mechanics and optics meet in a single substrate. In International Symposium on Optomechatronic Technologies (ISOT 2009), 21- 23 September 2009, Istanbul (pp. 445-450). Institute of Electrical and Electronics Engineers. https://doi.org/10.1109/ISOT.2009.5326161

DOI:

10.1109/ISOT.2009.5326161

Document status and date:

Published: 01/01/2009

\section{Document Version:}

Publisher's PDF, also known as Version of Record (includes final page, issue and volume numbers)

\section{Please check the document version of this publication:}

- A submitted manuscript is the version of the article upon submission and before peer-review. There can be important differences between the submitted version and the official published version of record. People interested in the research are advised to contact the author for the final version of the publication, or visit the $\mathrm{DOI}$ to the publisher's website.

- The final author version and the galley proof are versions of the publication after peer review.

- The final published version features the final layout of the paper including the volume, issue and page numbers.

Link to publication

\section{General rights}

Copyright and moral rights for the publications made accessible in the public portal are retained by the authors and/or other copyright owners and it is a condition of accessing publications that users recognise and abide by the legal requirements associated with these rights.

- Users may download and print one copy of any publication from the public portal for the purpose of private study or research.

- You may not further distribute the material or use it for any profit-making activity or commercial gain

- You may freely distribute the URL identifying the publication in the public portal.

If the publication is distributed under the terms of Article 25fa of the Dutch Copyright Act, indicated by the "Taverne" license above, please follow below link for the End User Agreement:

www.tue.nl/taverne

Take down policy

If you believe that this document breaches copyright please contact us at:

openaccess@tue.nl

providing details and we will investigate your claim. 


\section{Monolithic integration in Fused Silica: When Fluidics, Mechanics and Optics meet in a single substrate}

\author{
Yves Bellouard \\ Mechanical Engineering Department \\ Eindhoven University of Technology \\ Eindhoven, The Netherlands \\ y.bellouard@tue.nl
}

\author{
Ali A. Said, Mark Dugan, Philippe Bado \\ Translume Inc. \\ Ann Arbor, MI, USA
}

\begin{abstract}
We show that locally altering fused silica with femtosecond laser irradiation forms the basis for a novel manufacturing technology platform to produce highly integrated microsystems. In contrast to many common approaches that rely on combining materials to achieve particular functions, our scheme utilizes a single piece of material, whose properties are locally modified using femtosecond laser irradiation. This microsystem fabrication method is not only particularly attractive for optofluidics instruments but also for optomechanical devices.
\end{abstract}

Keywords-component; optofluidics; femtosecond lasers; fused silica; waveguides; monolithic integration; integrated devices.

\section{INTRODUCTION: SYSTEM INTEGRATION ISSUE}

Numerous micro- and nano- systems with various functionalities have emerged over the last decades. Starting in the seventies we have seen the advent of integrated circuits, followed by micro-mechanical systems, photonics and fluidics, and more recently the addition of organic material and biomolecules. These diverse micro- and nano- systems are becoming ever more complex machines performing sophisticated tasks.

Significant scientific and economic advantages are expected from the integration of these functionalities on a common platform. While the merger of electronics and micromechanics on silicon-MEMS platform is showing significant success, a true integration of photonics, micro-mechanics and fluidics on a common platform has yet to be successfully demonstrated and implemented. This is especially true when working with non-planar (i.e. 3D) devices, which is a fundamental requirement for many fluidic applications. Despite undisputable progresses, the number of commercially successful 3D microsystem applications remains limited and well below the perceived potential of the field. In this context, progress could be made by applying disruptive design approaches such as our proposed concept of 'system-material'.

\section{SYSTEM-MATERIALS}

\section{A. General concept}

Rather than building up a three-dimensional microdevice by combining and assembling materials, the 'system-material' approach starts with a single material, which is turned into a full system through local tailoring of its material properties. The material is no longer just an element of a device but becomes a device on its own. A system-material reacts to given stimuli, in a predictable and controllable manner with various degrees of complexity. It concurrently shares the characteristics of a system and of a material. Note that the objective is not to form a novel class of material that can be use as component (as for instance with so-called 'functional materials') but rather to directly introduce the system in the monolithic material. This system-material approach drastically reduces microsystems assembly steps (a significant source of fabrication cost, inaccuracy and reliability issues) and opens new design opportunities.

\section{B. Illustrations with fused silica and shape memory alloys}

While this paper is concerned mainly with fused silica, the concept of system-material can be applied to other materials, as we have shown in previous work [3][4]. Figure 1 illustrates the concept of system-material applied to a micro-actuator.

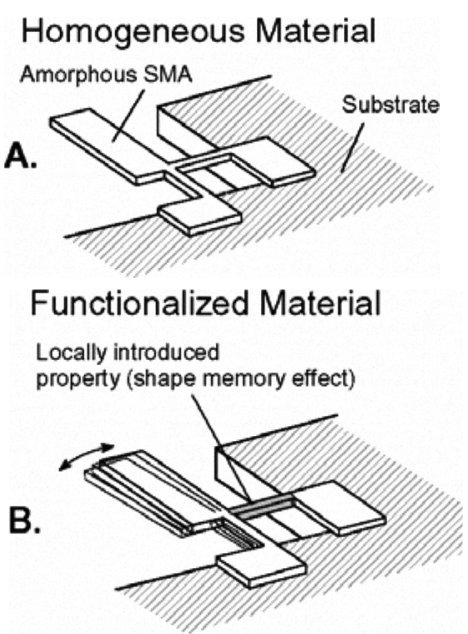

Figure 1. Ilustration of system-materials in micro-mechanics. A Shape Memory alloys micro-actuator: A. the microdevice is amorphous, homogeneous and does not produce any particular motion upon heating or cooling. B. the material is locally modified using an IR-laser beam that locally crystallizes the amorphous material (not shown). Thanks to this localized heat treatment, the monolithic device now produces a reversible semaphore-like motion upon heating and cooling [3]. 
This microdevice is made out of an amorphous Shape Memory Alloy film. As produced, the material is homogeneous and does not have any crystallographic structure. As a consequence, there is no possible phase transformation that can lead to shape memory properties. As deposited, it will not produce any specific motion upon heating (A). By spot heating the material using an infrared laser beam, one can locally crystallize it [3]. The combination of affected and non-affected zone causes a spontaneous, reversible mechanical motion upon heating and cooling (a semaphore-like motion), thus forming a mechanical actuator (B). Note that a fully crystallized material would also not produce a spontaneous reversible motion despite the presence of shape memory properties. This is the unique combination of affected and unaffected zones that create the reversible actuating function.

This example illustrates that a initially "inactive material" can be turned into a mechanical system by tailoring its properties locally.

Figure 3 illustrates the concept of system-material applied to a fused silica monolith. Prior to the localized modification steps, the glass is homogeneous and its optical properties are uniform across the volume. A hypothetical light signal would propagate through it following free-propagation laws (A).

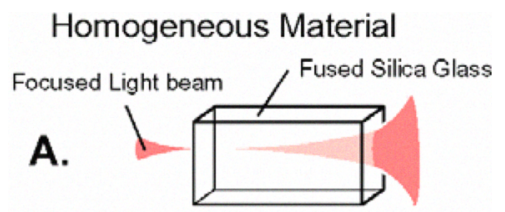

\section{Functionalized Material}

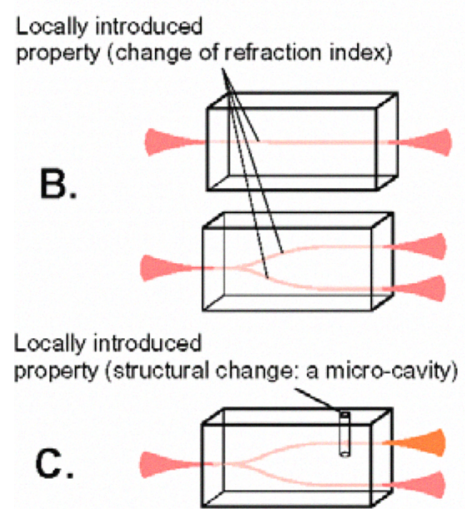

Figure 2. Illustration of system-materials in opto-fluidics. A piece of Fused Silica : A. the material is homogenous. B. The material was locally modified with a femtosecond laser. C. The material was locally modified with a femtosecond laser and then chemically etched. A probe signal (focused light beam) is applied on A, B and C).

Using a femtosecond laser (as we will see in the following section), one can locally increase the index of refraction of the glass. Due to the non-linear multi-photons absorption process that characterizes the femtosecond laser-matter interaction, this local modification can be performed anywhere inside the volume of the material. Applying this material modification effect along a defined scanning path (B and C), one can form any kind of optical waveguide system (a straight waveguide segments and a beam-splitter illustrate the concept in (B)).
Now, when our light probe is focus onto the input of the waveguide system, it no longer free-propagates through the fused silica, but rather follows a waveguided path inside the glass. The material has been tailored to accept a given stimulus (focused probe optical beam) and reacts in a controlled and predefined manner.

As we will see in the next paragraphs, the same laser-based approach can be used to also modify fused silica so that it will no longer be uniformly chemically etched as it would be if it had not been "pre-treated" by the laser. This process variant can be used to fabricate micro cavities (as illustrated in Figure 2C).

\section{Fused Silica: a "system-material"for opto-fluidics and opto-mechanics}

Synthetic Fused Silica (a-SiO 2$)$ is a glass that is transparent over a wide optical spectrum $(200 \mathrm{~nm}$ to $2.5 \mu \mathrm{m})$. Other key properties are its near-zero thermal expansion, an exceptionally good thermal shock resistance, low density, excellent chemical inertness, low dielectric constant and low dielectric loss. These properties make silica glass an interesting substrate material for optofluidics applications.

Typical of glasses, its atomic structure lacks long-range order. Its internal structure is described as a three-dimensional network of rings of various sizes, anchored around local $\mathrm{SiO}_{4}$ tetrahedrons. Fused silica has a high theoretical elastic limits (estimated at $15 \mathrm{GPa}$ or greater) but at the macroscale, it tends to break at much lower stress (typically a few tens of MPa) due to presence of surface flaws that act as crack nucleation sites [5]. As we will see, at the micro-scale this elastic limit can be significantly higher and reach values comparable to that of Silicon.

\section{FEMTOSECOND LASER MICROMACHINING OF FUSED SILICA}

\section{A. Femtosecond lasers}

Femtosecond lasers pulses are characterized by ultra-high peak power (Gigawatt $/ \mathrm{mm}^{2}$ or even Terawatt $/ \mathrm{mm}^{2}$ when focused) leading to an unconventional type of laser-matter interactions. Non-linear phenomena play a significant role and open new opportunities to tailor the matter in its intimate structure with an excellent spatial resolution and noticeably in three dimensions.

Although the peak power associated with this type of laser is huge, the average power remains very small, and the pulse energy is microscopic. For instance the structures illustrated in this paper are made with an average power of no more than $200 \mathrm{~mW}$.

Due to these characteristics, using these lasers, any material can be turned into a "plasma"; and the diffusion of heat away from the interaction region can be almost completely prevented [6][7]. As a consequence, the modification induced in the material occurs only at the laser focal point. The latter observation is of particular technological importance for the machining of "transparent material" (i.e. transparent at the laser 
wavelength): the material can be modified beneath its surface and throughout its volume.

In fused silica, femtosecond laser pulses can, not only locally increase the refractive index [8], they can also enhance the etching rate [10], introduce sub-wavelength patterns [12], create voids [13] or change its thermal properties [14]. By scanning the laser through the specimen volume [15], one can distribute, combine and organize these material modifications to form complex patterns to be used for instance as waveguides or fluidic channels.

\section{B. Waveguide writing}

Waveguide are written by scanning the beam over the specimen so that a continuous pattern is formed (see Figure 3 left) (see for instance [9]). The volume locally hit by the femtosecond laser (so-called Laser-Affected-Zone or LAZ) experiences a slight increase of refractive index ( $\Delta \mathrm{n}$ is typically a fraction of one-percent [16]). The LAZ shape and size can be characterized using either a refractive index map technique or more recently a novel technique based on Scanning Thermal Imaging [14]. Typically the LAZ has the shape of an ellipsoid stretched along the optical axis [17]. This shape is correlated to the laser beam parameters (beam-size, waist location and energy). The stretching along the vertical direction depends on the chosen focusing optics. Noteworthy, as femtosecond laser matter interaction involved non-linear processes, the LAZ can be smaller than the laser spot-size itself. Losses in our waveguides are typically less than $0.1 \mathrm{~dB} / \mathrm{cm}$ at $1550-\mathrm{nm}$. The waveguide cross-section can be shaped laser-writing multiple elemental lines next to each other [16]. A refractive map of a waveguide written with fs-laser is shown in Figure 3.

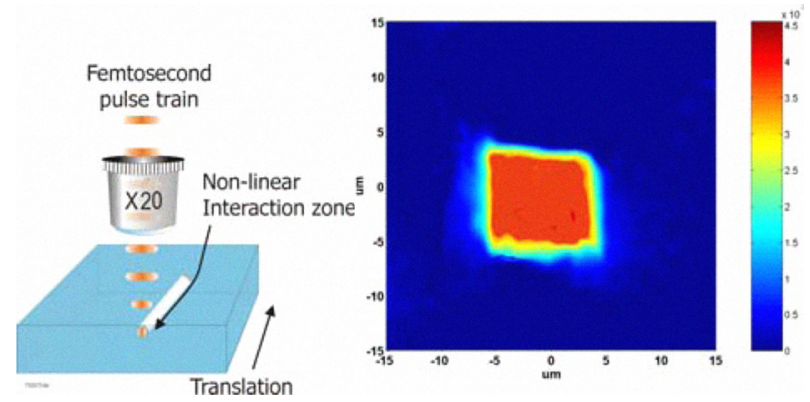

Figure 3. Left: Waveguide writing with femtosecond lasers. The laser beam is focused inside the glass piece. At the focal point, a plasma eventually forms when the threshold energy for non-linear absorption is reached. The exposed region sees it index increased. By translating the specimen under the laser

beam, one can form waveguides or other continuous structures made of contiguous laser affected zone. Right: Near-Field-Refractive index profile of a waveguide made of multiple adjacent Laser Affect Zones. This waveguides is

single mode at $1550 \mathrm{~nm}$ [16]. Yves, same comment- I don't see a need to repeat in the figure legend what is already in the main text.

Complex optical devices can be formed with this approach [18]. For instance Figure 4 shows a $50 \mathrm{GHz}$ unbalanced MachZehnder interferometer written with a femtosecond laser. [16]. Note that laser written device can be tuned. Once the device initial exposure is complete, the device can be tested and then slightly modified with additional femtosecond laser exposure to "tune" it.

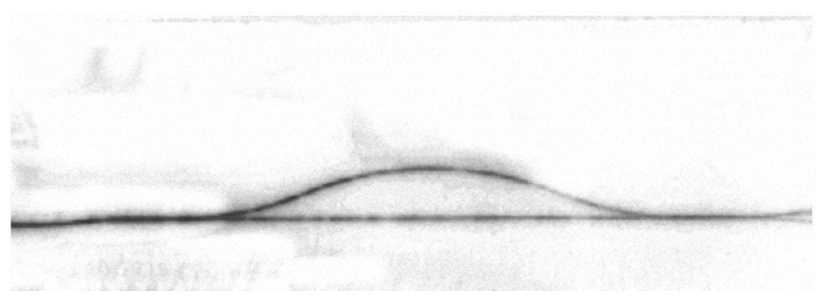

Figure 4. An interleaver fabricated with femtosecond laser direct writing [16]. Side view of a 50-GHz interleaver manufactured by us using the directwrite femtosecond process. The device, written in fused silica, is $5 \mathrm{~cm}$ long.

\section{Three dimenstional structures micromachining}

While femtosecond laser pulses can be used to directly ablate glass, it has been shown that the use of a two-step process that consists in first exposing the material with the laser and then etching the exposed patterns yield better results in term of quality and resolution.

To form three-dimensional structures the following twosteps procedure is applied (see Figure 5).

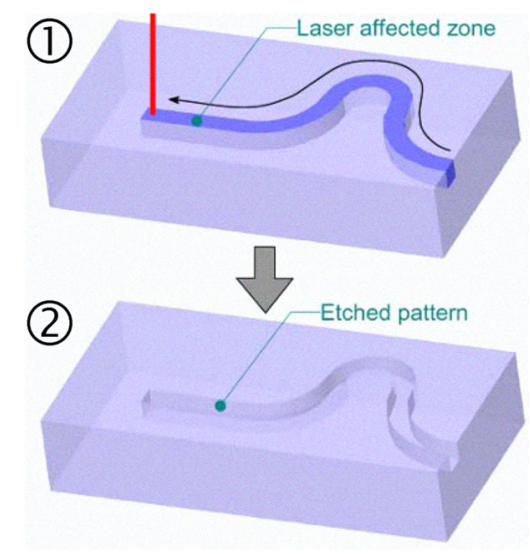

Figure 5. Process steps. 1- The material is exposed to femtosecond laser irradiation. 2 - The part is etched with Hydrofluoric acid. Exposed regions etch away much faster than unexposed regions.

The material is first selectively exposed by femtosecond laser rasterizing a pattern according to a technique described in [15]. The laser used in our experiment is a Ti:Sapphire laser (RegA from Coherent) operating at $800-\mathrm{nm}$. The pulse width is typically $100-\mathrm{fs}$, and the repetition rate is set at $250 \mathrm{kHz}$. The average power ranges from 20 to $400 \mathrm{~mW}$, which corresponds to pulse energies ranging from $55-\mathrm{nJ}$ to $1.6 \mu \mathrm{J}$. The linear spot size is approximately 1 micron in diameter at the focus. In our experiments, we used $20 \mathrm{X}$ and $50 \mathrm{X}$ long-working distance microscope objectives. Typical writing speeds are $0.5 \mathrm{~mm} / \mathrm{s}$ to $2 \mathrm{~mm} / \mathrm{s}$.

In a second step, the part is etched in a low-concentration HF bath. Concentrations between $2.5 \%$ and $5 \%$ are typically used. Etching time depends on pattern sizes and varies from one hour to several hours for the deepest structures. Following etching, the part is rinsed in de-ionized water and dried. The laser polarization has a strong effect on the etching efficiency as first reported by Hnatovski et al. [19]. 
To fabricate an optofluidics device, it is necessary to carefully control the etching process so that the waveguides are preserved. Figure 6 shows the time-dependent etching profile of a surface channel under which an optical waveguide was written [20]. The purpose of this test was to demonstrate that it was possible to form optical waveguides and microfluidic channels on a common substrate and that the two features could be processed at the same time. As shown on Figure 6, after 3 hours, the microfluidic channel is fully etched. Normally we would stop the etching process at this point, but for demonstration purposes, the etching process was allowed to continue. After 6 hours, a depression starts to be seen at the bottom of the channel. It is further revealed after 9 hours. This small secondary channel formed at the bottom of the main channel is the former optical waveguide that has been preferentially etched away. This experiment shows that a waveguide can be placed in the immediate vicinity of a microfluidic channel, and that its physical integrity will be preserved with extended time (here for 6 hours).

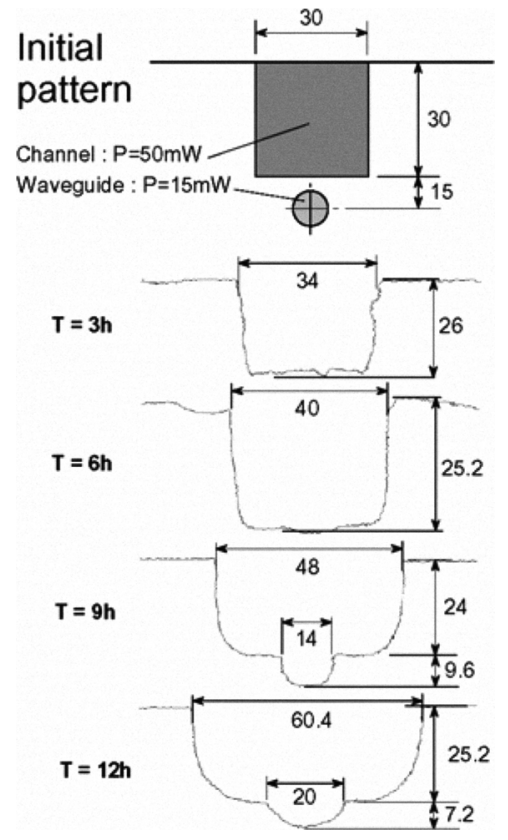

Figure 6. A channel and waveguide being gradually etch as the etching time is increased [20]. The etching profile was obtained by image processing and contour extraction of optical microscope images

To summarize, using femtosecond laser technique, a microdevice structure and function are directly "inscribed" into a single piece material turning fused silica into a systemmaterial. Note that other authors have demonstrated that similar approaches can be used with Foturan ${ }^{\circledR}$ (a photoetchable glass). Some of these works are reported in [22] and [23].

\section{OPTO-FLUIDIC INSTRUMENTS}

Using the system-material technology platform one can create a variety of (small) optofluidic instruments. Here we just present two examples from our early development effort. Figure 7 shows an optofluidic particle counter [24]. This simple instrument consists of a curved waveguide associated with a $100-\mu \mathrm{m}$ fluidic channel.
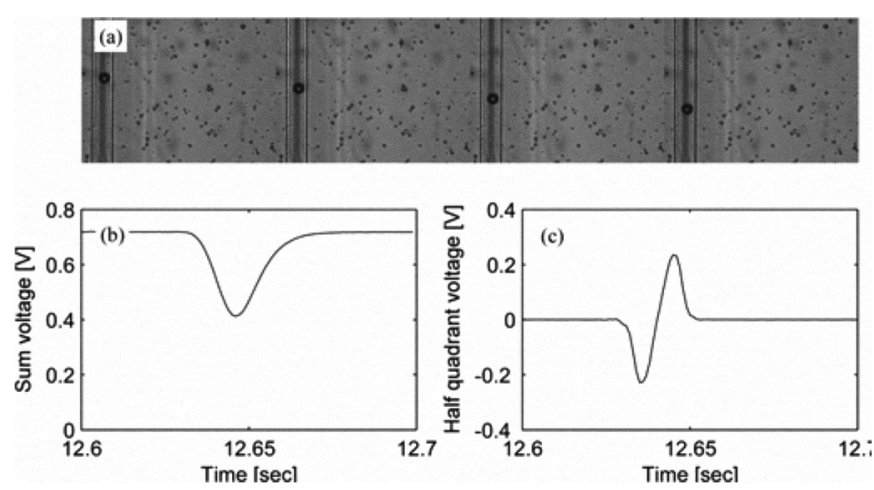

Figure 7. Detection of a flowing bead. (a) Sequence of captured images as a bead flows past the waveguide. (b) Total signal from all four quadrants of the photoreceiver. (c) Difference signal from two halves of the detector along the direction of the channel.

A collection of images as a 50-micron glass bead transits by the waveguide (faint horizontal line on the right in each frame) is shown in part a. Since the micro-particles under consideration are smaller than the beam diameter, we expect deviations in the light signal to arise from shadow effects. The collective signal shows a dip as the moving bead casts a shadow on the receiver. Observing the difference signal reveals a wavelet with a peak and then a trough (Figure 7c). When the bead traverses in the opposite direction, we detect a timereserved wavelet. Hence by looking at the difference signal and determining the peak-trough sequence we can determine the direction of flow of the micro-particle. Due to axial symmetry of the bead, the wavelet is negatively symmetric about its midpoint. Finally, from the extent of the wavelet we can estimate the size of the micro-particle provided its speed is known or vice-verse. In this example, from the image sequence we determine the bead diameter to be $61+/-4 \mu \mathrm{m}$, and the speed to be $7.3+/-0.2 \mathrm{~mm}$. Using this speed we estimate, from the extent of the difference signal wavelet, the size of the bead to be 66 $+/-8 \mu \mathrm{m}$ which is in agreement with the image- based value.

Figure 8 illustrates another example of optofluidics instruments. This instruments was proposed in 2004 [27] for analyzing the density of various type of liquids through absorption measurements.

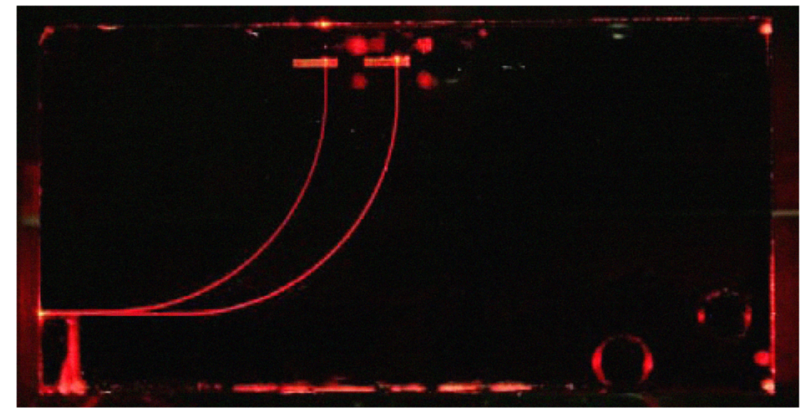

Figure 8. Optofluidic instruments for absorption measurements in liquid.

The device as two cuvettes seen in the upper part of the picture and two curved waveguides originating from the same source. The glass piece is about $2 \mathrm{~cm}$ wide and $5 \mathrm{~cm}$ long.

The principle is quite simple. It uses two curved waveguides to locally probe two small cuvettes containing two liquids. The two waveguides merge to form just one connected 
to a single laser source. The splitting ratio is about $50 / 50$ between the waveguides arms. In a way this device is similar to beam splitter in traditional free-space optics. One cuvette is filled with a reference liquid while the second cuvette contains the liquid under scrutiny.

Design possibilities are nearly infinite using a direct write process. Direct optical processing of the signal can be combined with complex fluidics channels or simple reservoirs. We are just at the beginning of this new field of research.

Other groups recently reported integrated optofluidics devices (see for instance [25], [26]).

\section{OPTO-MECHANICS}

Femtosecond laser patterning, combined with HF etching, provides a way to carve out any shape from fused silica (as long as the acid can reach the patterned area). Using this approach one can make not only fluidics structures as shown above, but also mechanical flexures (i.e thin beam-like structures) that can be elastically deformed. This fundamental mechanical element can be used to create complex optomechanical devices. We previously presented a mechanical sensor [29] where flexures and waveguides were all part of a monolithic fused silica substrate. This structure withstands stress in excess of $500 \mathrm{Mpa}$, and in one case in excess of $2 \mathrm{GPa}$ [30]. Another illustration of such an optomechanical device is shown below.

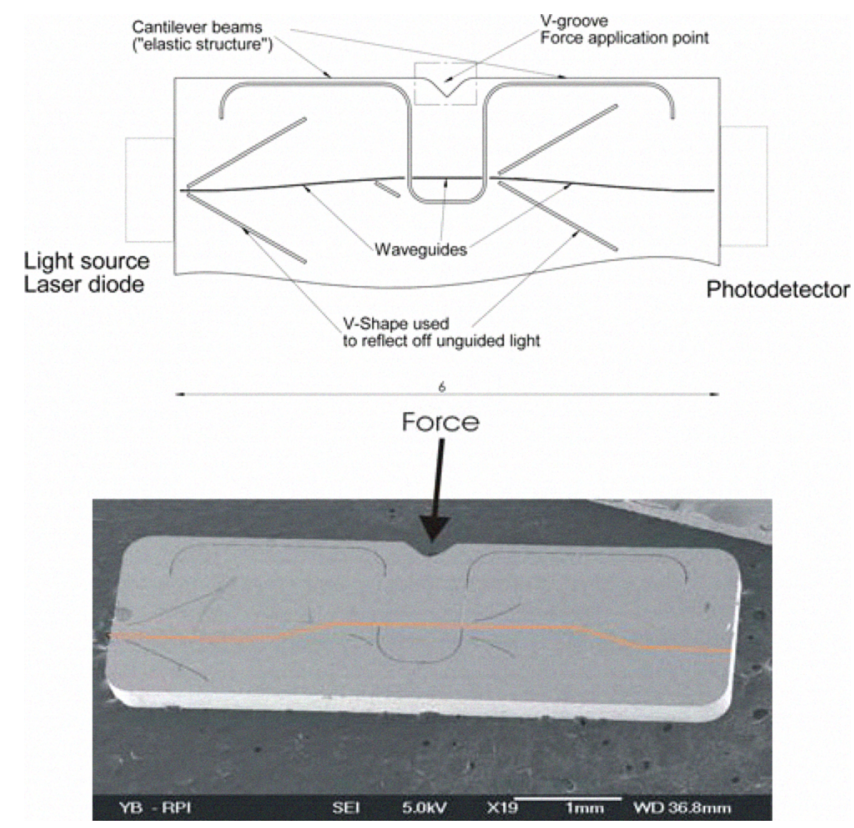

Figure 9. Micro-force sensor fabricated out of a 500-micron thick fused silica wafer with the femtosecond direct write processes. On the top the design which consists of a glass flexure a flexure made of two 40 microns-thin bars that holds a central portion on which a V-groove is machined. The flexure has a low bending stiffness along the $\mathrm{z}$ direction. It is used in its linear regime (small deflection). A waveguide divided in three portions is "written" below the surface, it crosses the structure along the $\mathrm{X}$-axis. Through measurement of the optical attenuation one can extract the flexure position. On the right the micro-force sensor as fabricated (the waveguide is overlaid in orange).
The working principle is the following. A waveguides is written and span across the mechanical structure. Part of the waveguide moves when the cantilever beam is deformed. When such movement occurs, it locally misaligns the waveguides sections inducing losses. Through measurement of the optical attenuation one can extract the flexure position. This method provides an efficient way to couple optics and micromechanics.

\section{CONCLUSION AND FUTURE PROSPECTS}

In this paper, we have seen that femtosecond lasers can be used to efficiently tailor the material properties of fused silica so to create, not only optical functions (such as waveguides), but also mechanical (flexures) or fluidics (micro-channels) elements.

These functions can be combined to form complex optofluidics or optomechanical devices or a combination of both in a single substrate. This dramatically reduces the fabrication complexity and opens new horizon for further integration at the micro-/nano- scale.

\section{REFERENCES}

[1] M. Madou, "Fundamentals of Microfabrication: The Science of Miniaturization," Taylor and Francis Ltd, ISBN: 0849308267, Boca Raton (2002)

[2] Y. Bellouard, $\mathrm{PhD}$ Dissertation, 'Conception de dispositifs en alliage à mémoire de forme,' EPFL, No 2308 (2000).

[3] Y. Bellouard, T. Lehnert, R. Clavel, T. Sidler, R. Gotthardt, Laser annealing of shape memory alloys: A versatile tool for developing smart micro-devices (2001) J. Phys. IV : JP, 11 (8), pp. Pr8571-Pr8576

[4] Y. Bellouard, T. Lehnert, J.-E. Bidaux, T. Sidler, R. Clavel, R. Gotthardt, Materials Science and Engineering A273-275, pp. 795-798 (1999).

[5] See 'Treatise on Materials Science and Technology' by Minoru Tomozawa, Robert H. Doremus, Published by Academic Press, 1982, ISBN 0123418224,9780123418227 as a general reference.

[6] D. Du, X. Liu, G. Korn, J. Squier, and G. Mourou, Appl. Phys. Lett. 64, 233071 (1994).

[7] S.S. Mao, F. Quéré, S. Guizard, X. Mao, R.E. Russo, G. Petite, P. Martin, Applied Phys. A 79, 1695-1709 (2004).

[8] K. M. Davis, K. Miura, N. Sugimoto, and K. Hirao, Opt. Lett. 21, 17291731 (1996).

[9] S. Nolte, M. Will, J. Burghoff, and A. Tünnermann, "Ultrafast laser processing: new options for three-dimensional photonic structures," $\mathrm{J}$. Modern Optics. 51, 2533-2542 (2004)

[10] A. Marcinkevicius, S. Juodkazis, M. Watanabe, M. Miwa, S. Matsuo, H. Misawa, and J. Nishii, Opt. Lett. 26, 277-279 (2001).

[11] Y. Shimotsuma, P. G. Kazanski, Q. Jiarong, and K. Hirao, "SelfOrganized Nanogratings in Glass Irradiated by Ultrashort Light Pulses," Phys. Rev. Lett. 91, 247405 (2003).

[12] R. Taylor, C. Hnatovsky, E. Simova, Applications of femtosecond laser induced self-organized planar nanocracks inside fused silica glass. Laser \& Photonics Review 2, 26-46 (2008).

[13] E. N. Glezer, M. Milosavljevic, L. Huang, R. J. Finlay, T. Her, J. Paul Callan and E. Mazur, "Three-dimensional optical storage inside transparent materials," Opt. Lett. 21, 2023-2025 (1996).

[14] Y. Bellouard, M. Dugan, A. Said, P. Bado, Appl. Phys. Lett. 89, 161911 (2006); DOI: 10.1063/1.2363957

[15] Y. Bellouard, A. Said, M. Dugan, P. Bado, Optics Express 12, 21202129 (2004) 
[16] P. Bado, A. Said, M. Dugan, T. Sosnowski, and S. Wright "Dramatic improvements in waveguide manufacturing with femtosecond lasers," in NFOEC, Dallas, Sep 2002

[17] Y. Bellouard, E. Barthel, A. A. Said, M. Dugan, and P. Bado, Opt. Express 16, 19520-19534 (2008).

[18] K. Minoshima, A.M. Kowalevicz, I. Hartl, E.P. Ippen, and J.G. Fujimoto, "Photonic device fabrication in glass by use of nonlinear materials processing with a femtosecond laser oscillator," Optics Letters, vol. 26, Oct. 2001, pp. 1516-1518.

[19] C. Hnatovsky, R. S. Taylor, E. Simova, et al., Opt. Lett. 30, 1867-1869 (2005)

[20] Y. Bellouard, A. Said, M. Dugan, and P. Bado, "Monolithic threedimensional integration of micro-fluidic channels and optical waveguides in fused silica," Materials Research Society Symposium Proceedings, 2003, pp. 63-68.

[21] A. Said, M. Dugan, P. Bado, Y. Bellouard, A. Scott, J. Mabesa, Photonics West, LASE (2004).

[22] Y. Cheng, K. Sugioka, K. Midorikawa, M. Masuda, et al., Opt. Lett. 28, 55-57 (2003).

[23] Y. Hanada, K Sugioka, H. Kawano, I. Ishikawa, A. Miyawaki, K. Midorikawa. "Nano-aquarium for dynamic observation of living cells fabricated by femtosecond laser direct writing of photostructurable glass." Biomedical Microdevices 10, 403-410 (2008).

[24] V.K. Pahilwani, Y. Bellouard, A.A. Said, M. Dugan, and P. Bado, "Insitu optical detection of mesoscale components in glass microfluidic channel with monolithic waveguide," Optomechatronic Actuators and Manipulation III, Lausanne, Switzerland: SPIE, 2007, pp. 67150H-6.

[25] R. W. Applegate Jr., J. Squier, T. Vestad, et al., Lab Chip, (2006), 6, 422 - 426, DOI: 10.1039/b512576f

[26] R. Martinez Vazquez, R. Osellame, et al., Lab Chip, (2009), 9, 91 - 96, DOI: $10.1039 / \mathrm{b} 808360 \mathrm{f}$

[27] A. Patillon, MSc Report, Rensselaer Polytechnic Inst. and ENSMM, Nov. 2004.

[28] Y. Bellouard, A. A. Said, M. Dugan, and P. Bado, Proceedings of SPIE Vol. 7203, 72030M (2009).

[29] Y. Bellouard, A. Said, P. Bado, Optics Express 13, 6635-6644 (2005).

[30] Y. Bellouard, A.A. Said, M. Dugan, and P. Bado, "High strength fused silica flexures manufactured by femtosecond laser," Commercial and Biomedical Applications of Ultrafast Lasers IX, San Jose, CA, USA: SPIE, 2009, pp. 72030M-8. 